\title{
Pergelaran Simphoni Keroncong Moeda \#9: Menimbang Ruang antara Musik Dulu dan Kini
}

\author{
Mei Artanto \\ Program Studi Pendidikan Musik, Fakultas Seni Pertunjukan, \\ Institut Seni Indonesia Yogyakarta \\ Email: flautacloth@gmail.com
}

\begin{abstract}
Simphoni Keroncong Moeda (SKM) \#9 is a space for the actualization of the Keroncong Muda Yogyakarta community in voicing keroncong music so that the younger generation is interested. Carrying a combination of musical content, SKM is present when there is a lack of appreciation from young people towards keroncong music. Armed with Western classical music knowledge from the arranger and his musicians as creative capital, the musical identity of keroncong music and other music such as campursari, dangdut, and pop is nicely packaged in orchestra music. This tendency follows what the logic of popular culture promotes by John Fiske as 'art in between'. 'Art is in between' becomes a musical identity playing room of SKM in weighing musical aspects of keroncong music and other music that is processed using popular creativity in the structure and form of music. For SKM, the space between being a field to weigh the extent of musical aspects in music used to be an aesthetic treat following the current trend of music development without losing the substantial educational value of keroncong music.
\end{abstract}

Keywords: keroncong music, popular culture, Simphoni Kerontjong Moeda, Yogyakarta

Abstrak: Simphoni Keroncong Moeda (SKM) \#9 menjadi ruang aktualisasi komunitas Keroncong Muda Yogyakarta dalam menyuarakan musik keroncong agar diminati oleh generasi muda. Mengusung konten perpaduan musical, SKM hadir dikala sepinya apresiasi anak muda terhadap musik keroncong. Berbekal pengetahuan musik klasik Barat dari para arranger dan musisinya sebagai modal kreatif, identitas musikal dari musik keroncong dan musik lainnya seperti campursari, dangdut, dan pop dikemas secara apik dalam balutan musik orkestra. Kecenderungan ini mengikuti apa yang ditawarkan logika budaya populer yang diusung oleh John Fiske sebagai 'seni berada di antara'. 'Seni berada di antara' menjadi ruang permainan identitas musikal dari SKM dalam menimbang aspek-aspek musikal dari musik keroncong dan musik lainnya yang diolah menggunakan kreatifitas populer secara struktur dan bentuk musiknya. Bagi SKM ruang antara menjadi medan untuk menimbang sejauh apa aspek musikal dalam musik dulu menjadi suguhan estetis mengikuti kecenderungan perkembangan musik saat ini tanpa kehilangan subtansi nilai edukasi dari musik keroncong.

Kata kunci: musik keroncong, budaya populer, Simphoni Kerontjong Moeda, Yogyakarta

\section{PENDAHULUAN}

Alunan khas bunyi intrumen musik keroncong seperti cak, cuk, cello, dan gitar, yang dibarengi dengan alunan musik orkestra telah membawa dan memberi warna yang berbeda bagi setiap lagu yang dibawakan Simphony Kerontjong Moeda (SKM) pada malam itu, 25 Juni 2019 di Embung Langensari, Yogyakarta. Sebut saja seperti lagu yang hari ini banyak diketahui oleh para milenial, seperti lagu Pamer Bojo dan Banyu Langit dari Didi Kempot. Dua lagu yang memiliki karakter kuat secara musikal dalam garapan campursari tersebut, malam itu nampak tampil dengan nuansa musikal berbeda di acara Simphony Kerontjong Moeda \#9. Selain dua lagu dari Didi
Kempot, SKM juga menggarap lagu-lagu berkarakter musikal kuat seperti lagu dangdut dari dua grup yang sedang digandrungi di Yogyakarta, dan memiliki banyak viewer di Youtube, yaitu Guyon Waton dan Om Wawes. Malam itu, lagulagu dengan identitas musikal yang khas dari musik campursari dan dangdut disulap secara apik oleh SKM \#9 melalui balutan musik keroncong dan orkestra.

Pada pergelaran kali ini, kembali SKM mengusung perpaduan musik keroncong dan orkestra sebagi konten musikal yang ditawarkan, dan itu seperti dalam pergelaran di tahun-tahun sebelumnya. Melalui konten perpaduan musik 
keroncong dan orkestra, SKM telah memberi warna dan angin segar bagi geliat musik keroncong di Yogyakarta khususnya untuk mengenalkan kembali musik keroncong kepada generasi muda. Hal menarik dari SKM selain suguhan format pergelaran yang menggunakan orkestra, yaitu terkait bagaimana dalam tajuk SKM \#9 ini SKM dapat memadukan musik 'dulu' (secara historis), seperti musik keroncong dan orkestra dengan karya musik saat ini, seperti lagu-lagu dari Didi Kempot, Guyon Waton, dan Om Wawes yang justru banyak digandrungi oleh anak muda saat ini, khususnya di Yogyakarta dan sekitarnya. Padahal secara musikal, masing-masing musik tersebut, yaitu campursari, dangdut, musik keroncong, dan orkestra, memiliki karakter yang sangat kuat, baik dari gaya musikal, garapan, dan format instrumen musiknya. Artinya bukan perkara mudah untuk memadukan beragam identitas musikal dari musik tersebut kedalam bentuk sajian pergelaran. Pasalnya jika penggarapan musik tersebut tidak cukup cermat, maka bukan perpaduan apik yang dicapai tetapi justru karakter dan identitas musikal dari musik tersebut tidak dapat tersampaikan secara baik kepada pendengar. Lantas apa yang sedang diupayakan dan ditawarkan oleh SKM \#9 dengan konten perpaduan musik keroncong dengan musik lainnya? Tentu SKM memiliki maksud tersendiri yang kiranya penting untuk disampaikan melalui konsep musikal yang diusung. Pasalnya jika tidak, konten sajian semacam ini memiliki resiko kegagalan yang cukup besar untuk dilakukan. Terlebih jika maksud dari konten tersebut berkaitan erat dengan pelestarian dan pendidikan publik melalui pergelaran musik.

Merujuk penjelasan di atas, lantas membuat penulis tertarik untuk menilik sejauh apa praktik yang dilakukan SKM dalam menegosiasikan identitas musikal dari musik keroncong, orkestra, campusari, dan dangdut dalam pergelaran SKM \#9. Namun sebelum beranjak menilik sejauh apa perpaduan musikal yang ada pada pergelaran SKM \#9, sejenak kita dapat mendengarkan pergelaran dari SKM \#9 melalui penelusuran youtube menggunakan smartphone yang kita miliki. Pada menu pencarian, silahkan menuliskan Simphony Kerontjong Moeda untuk mencari video terkait. Setelah itu, maka di layar smartphone akan terpampang banyak pilihan video SKM dari pergelaran tahun-tahun sebelumnya. Saran penulis yaitu pilih video SKM \#9, seperti lagu berjudul Lungaku dan Sebatas Teman dari Guyon Waton, atau lagu Banyu Langit dan Pamer Bojo dari Didik Kempot yang dinyanyikan oleh Paksi Raras Alit. Selamat mendengarkan.

\section{KAJIAN PUSTAKA}

Mendengarkan musik menjadi aktvitas penting dalam sebuah penelitian yang memiliki objek penelitian sebuah pergelaran musik. Hal itu dilakukan guna mendapati data yang berkaitan dengan aspek musikal dan non-musikal yang hadir dalam sebuah pergelaran, seperti mendengarkan dan mengamati pergelaran SKM \#9. Selain mendengarkan dan mengamati pergelaran SKM \#9, hal yang juga penting dalam sebuah penelitian yaitu melakukan kajian pustaka. Kajian pustaka ini dilakukan guna mendapati informasi dan data yang berguna untuk memetakan di mana posisi penelitian ini dengan penelitian sebelumnya. Tidak hanya itu, fungsi dari kajian pustaka dalam penelitian ini juga untuk menambah dan mengkonfirmasi jika terdapat kemiripan data maupun mendapati data yang belum diperoleh oleh peneliti.

Tulisan pertama dalam kajian pustaka ini diambil dari artikel Nugrahanstya Cahya Widyanta dengan judul Efektivitas Keroncong Garapan Orkes Keroncong Tresnawara Terhadap Audiensi Generasi Muda. Tulisan yang terbit di Jurnal Kajian Seni Vol. 3, No. 2 Tahun 2017 menyoal tentang kreativitas pada Orkes Keroncong Tresnawara dalam menggarap lagu-lagu keroncong. Dalam proses pengamatan penggarapan lagu keroncong dari Orkes Keroncong Tresnawara, Nugrahanstya menemukan beberapa aspek musikal yang menjadi kekhasan gaya keroncong garapan Orkes Keroncong Tresnawara seperti pada gaya vokal, terdapat singkopasi, unisono, dan penggunaan akord subtitusi (Widyanta, 2017: 167 - 171). Selain memperoleh kekhasan pada gaya musikal dalam proses penggarapan lagu-lagu keroncong, Nugrahastya juga menyoal tentang makna dari adanya gaya musikal garapan Orkes Keroncong Tresnawara. Penelusuran terkait pemaknaan atas gaya musikal ini, Nugrahastya mengamati pemaknaan tersebut dari perspektif penonton, yang untuk konteks tulisan tersebut lebih mengamati pada pemaknaan dari para generasi muda. 
Tulisan kedua dari Antisipasi Iman Nehe dengan judul Keberadaan Orkes Keroncong KKAJ Di Jombang yang terbit dalam Virtuoso (Jurnal Pengkajian dan Penciptaan Musik) Vol. 2, No. 2, November 2019. Artikel ini menjelaskan tentang geliat dan eksistensi orkes keroncong Komunitas Keroncong Anak Jombang (KKAJ) dalam upaya melakukan konservasi musik keroncong di wilayah Jombang (Nehe, 2019: 71). Bagi Nehe keberadaan KKAJ di Kabupaten Jombang amatlah penting, hal itu dikarenakan KKAJ dalam melakukan konservasi musik keroncong cukup aktif melakukan regenasi bagi anggotanya, yaitu dengan mendatangi beberapa SMA di Jombang guna melakukan perekutan anggota (2019: 75). Berdasarkan hal itu, kehadiran dari KKAJ di Jombang sebagai ruang untuk mempelajari keroncong sangatlah penting, terlebih bagi generasi muda agar mereka dapat mengenal dan mencintai keroncong secara mendalam.

Tulisan ketiga dari Dedi Novaldi, G. R. Lono Lastoro Simatupang, dan Sal Murgiyanto dengan judul Pasar Keroncong Kotagede 2017: Sebuah Kajian Event. Artikel yang terbit di Jurnal Kajian Seni Vol. 05, No. 02, April 2019 menyoal tentang Pasar Keroncong Kotagede 2017 jika ditinjau dalam perspektif event studies akan berada dalam kategori seperti apa (Novaldi, Simatupang, dan Murgiyanto, 2019: 192). Melalui perspektif even studies Novaldi memiliki temuan bahwa Pasar Keroncong Kotagede 2017 bisa masuk kedalam dua kategori pada typologi of planned events, yaitu konser (arts and entertaiment) dan festival (cultural celebrations) (2019: 197, 200, dan 202). Akan tetapi dari penjelasan dua ketegori tersebut, Novaldi justru menegaskan bahwa kehadiran event Pasar Keroncong Kotagede 2017 ini merupakan sebuah bentuk festival di mana seluruh anggota masyarakat Pasar Kotagede, baik langsung maupun tidak, ikut terlibat dalam proses penyelenggaraannya (2019: 205 - 206). Yang dalam konteks ini dengan menyajikan konser (arts and entertaiment) atau pergelaran musik keroncong. Mengamati tulisan di atas, penulis mendapati bahwa topik dari penelitian ini sangatlah berbeda dengan ketiga tulisan tersebut. Kesamaan yang ada, yaitu terdapat pada pengambilan objek yaitu musik keroncong, namun jika ditilik secara rinci, baik situasi dan latarbelakang pada penelitian ini sangatlah berbeda, yaitu dengan mengambil objek pergelaran SKM \#9.

\section{METODE PENELITIAN}

Pada penelitian ini penulis menggunakan metode kualitatif. Penggunaan metode kualitatif ini dimaksudkan agar penulis dapat menguraikan secara mendalam terkait bagaimana proses dan cara dari SKM \#9 dalam menghadirkan musik dulu dan kini dalam sebuah pergelaran musik sehingga dalam penyajian datanya dapat dilakukan dengan langkah dan tindakan yang tepat (Rohidi, 2011: 48). Proses pengumpulan data dilakukan dengan cara observasi langsung, di mana pengalaman penulis sebagai musisi yang ikut serta dalam penyelenggaraan SKM \#9 menjadi pintu masuk dalam mengumpulkan data. Selain itu proses pengumpulan data dilakukan melalui proses pengamatan audio visual yang terdapat di youtube. Hal ini dilakukan guna mendapata data yang terkait dengan aspek musikal. Setelah data diperoleh hal selanjutnya yaitu melakukan analisis data dengan menggunakan model Miles dan Huberman yaitu reduksi data, penyajian data, dan verivikasi data (Sugiono, 2015: 337 - 345). Pada proses analisis data ini, penulis akan menggunakan perspektif dari John Fiske terkait telaahnya atas budaya populer, di mana ruang antara menjadi wilayah penting dalam memahami seni budaya populer (Fiske, 2011: 40). Dan pergelaran SKM \#9, bagi penulis sedang bermain dalam ruang antara tersebut, di mana musik dulu, yaitu keroncong, dipadukan dan dicampurkan dengan musik saat ini, yaitu dangdut dan campursari.

\section{PEMBAHASAN}

\section{Mengenal Simphoni Kerontjong Moeda}

Sembari mendengarkan video SKM \#9 di youtube, barangkali kita dapat melanjutkan pembicaraan upaya negosiasi musikal yang dilakukan oleh SKM dengan penelusuran secara singkat kemunculan Simphony Kerontjong Moeda atau sering disebut SKM di Yogyakarta. SKM, saat ini dapat dikatakan sebagai wadah bagi temanteman muda yang memiliki ketertarikan terhadap musik keroncong. Mayoritas dari mereka, yaitu penggagas, konseptor, pengorganisir acara, aranger, hingga para musisi yang terlibat disetiap pergelaran merupakan para alumni SMK N 2 Kasihan Bantul atau sering disebut dengan Sekolah Menengah Musik (SMM) Yogyakarta. Berbekal pengetahuan musik yang diperoleh dari jenjang 
tersebut, mereka bersama-sama membuka ruang bagi teman-teman generasi muda yang memiliki ketertarikan terhadap musik keroncong untuk bergabung melestarikan musik ini.

Kehadiran SKM sejauh ini mendapat apresiasi dan disambut baik oleh masyarakat Yogyakarta. Hal itu dapat dilihat dari rutinnya SKM menggelar pergelaran musik sejak tahun 2009, hingga pergelaran SKM \#9 di tahun 2019. Dilansir dari blog pribadi salah seorang punggawa SKM, yaitu Ari Kancil, mengatakan bahwa munculnya komunitas ini, yang bernama Keroncong Muda Yogyakarta didasari oleh rasa keprihatinan atas minimnya minat anak muda terhadap musik keroncong di Yogyakarta (arikantjil.blogspot.co.id, diunduh 20 Agustus 2019). Rasa keprihatinan tersebut lantas membuat teman-teman Keroncong Muda Yogyakarta merancang program-program guna menarik minat generasi muda untuk mencintai musik keroncong, salah satunya yaitu membentuk Simphony Kerontjong Moeda. Sejak kemunculannya, SKM mengusung konsep suguhan sajian musik keroncong dengan konten anak muda dan dimainkan oleh para musisi muda. Hadirnya para musisi muda yang tampil disetiap pergelaran SKM turut menguatkan pesan bahwa musik keroncong tidak lagi identik dengan musik tempo dulu yang hanya dimainkan oleh para generasi lama. Ari Kancil juga menjelaskan bahwa SKM mencoba menyuguhkan musik keroncong dengan berbagai variasi, baik keroncong asli dan keroncong garapan dengan memadukan berbagai genre musik (arikantjil.blogspot.co.id, diunduh 20 Agustus 2019). Hal itu dilakukan guna musik keroncong dapat secara mudah diterima oleh generasi muda yang pada akhirnya minat mempelajari musik keroncong dapat tumbuh dibenak para generasi muda, khususnya di Yogyakarta dan sekitarnya. Melalui upaya tersebut Ari Kancil menaruh harapan agar para generasi muda dapat kembali memiliki ketertarikan terhadap musik keroncong secara mendalam.

\section{SKM \#9 dan Jejak Memadukan Keroncong dengan Orkestra}

Sekelumit penjelasan tentang tujuan hadirnya SKM dapat memberi pengetahuan bagi kita bahwa musik keroncong dapat dinikmati dan dimainkan secara berbeda oleh generasi muda. Dan perihal konsep musik yang diusung, yaitu berbagai variasi dari musik keroncong, dapat dicermati dalam pergelaran SKM \#9, di mana musik keroncong dibawakan secara apik dengan balutan orkestra yang berpadu dengan musik lainnya. Sajian yang menarik ini, penulis rasakan sejak mengikuti latihan hari pertama guna menyiapkan pergelaran SKM \#9. Pada kesempatan tersebut penulis ikut serta sebagai pemain flute, dan itu seperti di tahun-tahun sebelumnya ketika terlibat dalam pergelaran SKM. Ketertarikan penulis atas suguhan pergelaran SKM \#9 yang begitu apik turut disertai pertanyaan terkait sejauh apa upaya negosiasi musikal yang dilakukan dalam pergelaran SKM \#9. Pasalnya baik lagu-lagu hits hari ini seperti lagu dari Didi Kempot, Guyon Waton, dan Om Wawes dan lagu-lagu keroncong dari Kusbini dapat disajikan secara berbeda dari nuansa lagu sebelumnya.

Mengamati apa yang dilakukan oleh SKM ini, yaitu proses memadukan musik keroncong dengan orkestra, nampaknya bukan satu-satunya ruang dalam geliat musik keroncong di Yogyakarta. Jika ditilik beberapa tahun sebelum SKM muncul, yaitu di tahun 2000-an upaya menggabungkan musik keroncong dengan orkestra sebenarnya telah dilakukan oleh Singgih Sanjaya dengan Light Keroncong Orkestra (Widyanta, 2016: 57). Bersama Light Keroncong Orkestra (LKO), Singgih Sanjaya juga mengusung misi untuk melakukan pelestarian dan pengembangan musik keroncong (http://www.tjroeng.com/?p=373 , diunduh 20 Agustus 2019). Bahkan jika ditengok jauh kebelakang, jauh sebelum Singgih Sanjaya dengan LKO, di tahun 1970-an perpaduan berbagai irama musik, seperti jazz, rock, dan lainya, dengan musik keroncong telah dilakukan oleh Budiman BJ bersama orkes keroncong Bintang Jakarta (Soeharto dan Sunurpraptomo, 1996: 44-45). Maka dengan pemaparan jejak dari upaya memadukan musik keroncong dengan musik lainnya di atas, sebenarnya hadirnya SKM dengan mengusung konsep memadukan keroncong dengan orkestra dalam konstelasi geliat musik keroncong nasional, terlebih di Yogyakarta bukanlah sesuatu yang baru. Akan tetapi yang menarik dari hadirnya SKM dalam geliat musik keroncong di Yogyakarta justru terletak pada hadirnya generasi muda, baik sebagai musisi, aranger, hingga kepanitiaan di SKM. 
Hemat penulis, kehadiran anak muda dalam upaya pengembangan musik keroncong menjadi modal penting, pasalnya yang mengetahui seluk beluk bagaimana dan hal apa saja yang menjadi ketertarikan generasi muda pada umumnya adalah anak muda itu sendiri. Artinya kehadiran SKM yang mayoritas roda penggeraknya adalah anak muda, sekirannya jika mengunsung konsep pergelaran tentu disertai dengan pertimbangan taste generasi muda, baik itu dalam konten musikal maupun repertoar yang disuguhkan. Dan itu nampak dalam pergelaran SKM \#9 di mana penataan panggung, konten musikal, hingga repertoar musik cenderung mengarah pada apa yang sedang hits dikalangan anak muda, khususnya Yogyakarta.

Melihat pergelaran musik SKM \#9, penulis menangkap bahwa apa yang sedang diupayakan oleh SKM yaitu agar musik keroncong kembali dekat dengan generasi muda begitu kental terasa. Hal ini dapat diamati dari repertoar yang disuguhkan, di mana mayoritas adalah lagu-lagu yang saat ini sedang hits di Yogyakarta, seperti lagu Pamer Bojo dan Banyu Langit dari Didi Kempot, serta beberapa lagu dari Guyon Waton dan OM. Wawes. Upaya menghadirkan lagu-lagu hits ini dalam balutan keroncong dan orkestra menjadi satu daya tarik tersendiri bagi pergelaran SKM \#9. Dan jika kita melihat audio visual yang ada di youtube, tentu dapat mendapati bagaimana respon penonton yang begitu ramai ketika lagulagu hits ini dibawakan. Bahkan tidak canggung para penonton juga ikut bernyanyi bersama SKM \#9. Berdasarkan hal seperti itu setidaknya upaya yang dilakukan SKM \#9 dalam memadukan musik keroncong, orkestra, dangdung, dan campursari dapat diterima oleh masyarakat, khususnya yang malam itu hadir secara langsung.

Hal yang justru sulit bagi penulis yaitu mencoba memasukkan praktik musik yang dilakukan SKM ini dalam kategori-kategori pengelompokan musik keroncong. Pasalnya sejauh ini, repertoar yang disajikan oleh SKM dapat mengarah pada tiga pengelompokan jenis musik keroncong, seperti keroncong garapan, keroncong beat, dan gaya keroncong.

Ditinjau secara historis, keroncong garapan muncul di tahun 1970-an di mana Orkes Studio Jakarta dalam acara Bintang Radio Televisi menggarap musik keroncong secara orkestra
(Ganap, 2011: 19). Pada umumnya, keroncong garapan merujuk pada upaya mengolah musik keroncong dengan perpaduan berbagai gaya musik, yang seringkali perpaduan tersebut secara struktur musik ditempatkan pada bagian intro, interlude, dan koda (1996: 44-45). Hal itu juga dipertegas oleh musisi keroncong senior di Yogyakarta, yaitu Andi Prihtyas Toko yang menjelaskan bahwa 'keroncong garapan itu keroncong yang diaransemen, kalau lagu keroncong ya kordnya divariasi, terus ada intro, koda' (Toko, 07 Juni 2018). Keroncong beat, secara historis muncul pada tahun 1960-an di mana komersialisasi musik sedang merebak kala itu sehingga membuat Brigadir Jenderal Pirngadi merasa perlu untuk memberi warna baru dalam musik keroncong melalui mengaransemen kembali lagu-lagu yang sudah ada, yang tidak hanya berkutat pada lagu keroncong saja melainkan juga mengaransemen lagu pop Barat (Widjajadi, 2007: 23-24, dan 2016: 44). Dan apa yang dilakukan oleh Brigadir Jenderal Pirngadi pada masa itu, bagi Philip Yampolsky disebut dengan catchall category yaitu sebuah upaya kreatif dalam membawakan keroncong yang keluar dari standar keroncong masa itu namun tetap mempertahankan idiom musik keroncong, yang kemudian dianggap olehnya sebagai pop kroncong (Yampolsky, 2010: 10). Sedangkan untuk gaya keroncong, Widjajadi menjelaskan bahwa upaya ini tidak lain merupakan bentuk ekspresi gaya musikal musik keroncong secara leluasa, baik hanya sekedar menempelkan gaya musikal keroncong atau memadukan dengan lagu apapun agar memiliki 'rasa keroncong' (2007: 4).

SKM \#9 dalam Ruang Antara Musik Dulu dan Kini

Mengamati penjelasan pengelompokan musik keroncong di atas, ketiganya memiliki kesamaan secara konsep musikal, yaitu mengolah musik keroncong secara kreatif agar berbeda dengan bentuk dan gaya musik sebelumnya. Dan sejauh pengamatan penulis terhadap repertoar yang disajikan dalam setiap pergelaran SKM, secara konsep musikal SKM dapat masuk ke dalam tiga pengelompokan di atas secara dinamis. Kedinamisan ini merujuk pada tujuan dari hadirnya SKM dalam geliat musik keroncong di Yogyakarta, yaitu memberi kemasan yang segar terhadap musik keroncong agar diminati generasi 
muda. Maka agar musik keroncong dapat diterima secara mudah oleh lintas kalangan, khususnya anak muda, kedinamisan secara musikal menjadi hal penting. Lantas untuk mencapai itu, aransemen musik dipilih oleh SKM sebagai konsep pengolahan musiknya.

Melalui aransemen musik sebagai pilihan pengolahan musikalnya, penulis melihat bahwa SKM sedang bermain-main pada 'ruang antara' musik dulu dan musik kini. Penyebutan musik dulu mengacu pada penggunaan musik keroncong dan orkestra yang kita tahu bahwa musik tersebut memiliki catatan historis panjang dalam perjalanan musik di Indonesia. Sejarah perjalanan musik keroncong dapat kita baca dalam buku yang berjudul Krontjong Toegoe karya Victor Ganap (2011) dan artikel yang ditulis oleh Philip Yampolsky (2010) dengan judul Kroncong Revisited: New Evidence from Old Sources. Untuk sejarah masuknya musik klasik Barat, seperti orkestra ke Indonesia dapat dilihat dalam buku yang berjudul Disseminasi Musik Barat ke Timur karya Triyono Bramantyo (2004), Tan Thiam Kwie: Celah-Celah Kehidupan Sang Maestro Pendidik Musik Tiga Zaman karya RM. Surtihadi (2008), dan Amir Pasaribu: Komponis, Pendidik \& Perintis Musik Klasik Indonesia karya Eritha Rohana Sitorus (2009). Merujuk pada catatan historis tersebut dalam tulisan ini penulis menyebut musik keroncong dan orkestra sebagai musik dulu yang diolah dan diaktualisasikan oleh SKM dengan kecenderungan perkembangan musik saat ini. Sedangkan musik kini, lebih mengacu pada karya musik pop yang muncul dan digandrungi saat ini oleh anak muda, seperti lagu-lagu yang dibawakan oleh SKM \#9 sebut saja lagu Pamer Bojo dan Banyu Langit dari Didi Kempot; lagu Lungaku dan Sebatas Teman dari Guyon Waton; dan lagu Dinggo Bukti dari Om Wawes.

Penjelasan di atas kiranya dapat menjadi poin penting untuk menilik sejauh apa praktik SKM dalam 'ruang antara' musik dulu dan kini. Ruang antara dalam konteks tulisan ini, mengacu pada kecenderungan budaya populer yang menghadirkan produk hiburan melalui mekanisme saling pinjam meminjam dan memadukan berbagi unsur dalam modus produksinya sehingga dapat mengkondisikan tubuh dalam pengalaman di antara (Heryanto, 2015: 22). Artinya, dalam upaya melestarikan musik keroncong dengan situasi perkembangan musik saat ini beserta berbagai tingkat apresiasi musik di masyarakat yang bervariasi, SKM tidak dapat melepaskan diri dari modus produksi yang ada dalam budaya populer. Permainan SKM di ruang antara tersebut nampak terlihat melalui kaca mata Fiske dalam melihat praktik budaya populer. Bagi Fiske, budaya populer telah menghadirkan kreatifitas populer yang turut serta dengan segala kemampuannya untuk membuat 'seni berada di antara' melalui pengolah segala hasil industri budaya (2011: 30 dan 40). Dan apa yang dijelaskan oleh Fiske di atas yang sedang dimainkan oleh SKM \#9 di repertoar sajian musik malam itu. Sebut saja seperti lagu Pamer Bojo dari Didi Kempot, dengan khas alunan musik keroncong melalui instrumen cak, cuk, dan cello beserta format orkestra, lagu campursari disajikan tanpa kehilangan rasa musik campursari. Hal serupa juga nampak pada lagu yang berjudul Dinggo Bukti dari Om Wawes, di mana konsep musik dangdut yang disisipi irama jazz pada lagu tersebut tetap dipertahankan oleh SKM \#9 walaupun digarap dengan balutan keroncong dan orkestra.

Sajian semacam itu, bagi penulis yang kala itu berposisi sebagai pemain merasa bahwa SKM sedang memainkan identitas musikal musik keroncong, orkestra, dangdut, dan campursari melalui aransemen musik sebagai pengolahan musikalnya. Pada pergelaran SKM \#9, identitas musikal musik keroncong tetap dihadirkan melalui permainan instrumen cak, cuk, dan cello secara engkel dan double dengan cara membaca partitur. Identitas orkestra disajikan melalui permainan dari strings section, woodwind section, dan brass section beserta cara mengolah musiknya yaitu aransemen musik yang menggunakan ilmu musik klasik Barat; untuk musik campursari dihadirkan melalui pilihan lagu Pamer Bojo dan Banyu Langit dan hadirnya combo band section; sedangkan identitas musikal dangdut dihadirkan melalui pilihan lagu dari Guyon Waton dan OM Wawes beserta permainan kendang yang begitu khas.

Permainan tersebut nampak pada pembagian porsi penempatan identitas musikal dalam struktur bentuk musiknya yang terkadang bertemu pada satu permaianan dibagian tertentu, dan terkadang dipisahkan dibagian tertentu. Pertemuan identitas musikal dari masing-masing jenis musik dan pemisahannya membuat lagu yang dibawakan oleh 
SKM \#9 ini terkesan menjadi abu-abu karena masing-masing identitas musikal sama-sama tampil kuat dalam sajiannya. Musik keroncong dalam konteks ini hanya diambil gaya permainan yang dibawakan oleh instrumen cak, cuk, dan cello sebagai penanda bahwa repertoar yang dimainkan memiliki rasa keroncong walaupun bukan lagu keroncong (2007: 3 dan 49).

Bagi penulis, sajian semacam itu seakan mengaburkan cita-cita melestarikan musik keroncong, pasalnya musik keroncong yang disajikan hanya mengambil gaya permainannya saja. Hal tersebut kiranya baik dilakukan sebagai upaya mengenalkan kembali musik keroncong kepada generasi sekarang melalui lagu-lagu atau jenis musik yang saat ini digandrungi oleh kalangan anak muda, khususnya Yogyakarta dan sekitarnya. Namun juga perlu ditimbang secara mendalam untuk memberi porsi lebih pada pengenalan bentuk musik keroncong pakem, seperti keroncong asli, langgam, langgam jawa, dan stambul, yang diaktualisasikan dengan musik yang berkembang saat ini. Jika hal itu dilakukan, maka apa yang di maksud oleh Fiske yang mengutip dari de Certau bahwa seni 'mengolah' dalam modus produksi budaya populer tidak hanya sekedar bertujuan untuk membuat masyarakat masuk dalam sistem kuasa industri melalui komoditas yang ditawarkan (2011: 28). Artinya sajian dari SKM \#9 ini diharapkan tidak masuk dalam jeratan budaya populer yang dimaksud Fiske di atas dengan berhenti pada hingar bingar pergelaran semata tanpa ada upaya keberlanjutan yang lebih dalam memahami musik keroncong oleh para pendengarnya. Terlepas dari catatan tersebut, keunggulan SKM saat ini terletak pada pengolahan aspek musikal dalam 'ruang antara' dari musik dulu dan musik kini. Melalui upaya semacam itu justru menjadikan SKM dinamis secara konteks pergelaran dan dapat dinikmati oleh berbagai kalangan dan usia.

\section{KESIMPULAN}

Upaya pelestarian terhadap musik keroncong di Yogyakarta saat ini sangat diperlukan guna melanjutkan kehidupan musik ini. Hal itu yang sedang diupayakan oleh SKM dalam kurun waktu kurang lebih sembilan tahun ini. Melalui upaya mengemas musik keroncong yang berpadu dengan musik hits dan digandrungi anak muda di wilayah Yogyakarta dan sekitarnya membuat pergelaran SKM sangat disayangkan jika dilewatkan. Upaya memadukan musik dulu dan kini sebagai konten musikal dalam setiap pergelaran menjadikan SKM berada dalam permainan dan pengkondisian budaya populer, yaitu ruang antara. Permainan yang penuh akan jerat kuasa industrialisasi di setiap modus produksi dalam ruang antara ini diikuti oleh SKM dengan penuh negosiasi. Negosiasi tersebut terlihat dari cara bagaimana SKM menimbang ruang antara musik dulu dan kini melalui aransemen musik yang menghadiran identitas musikal secara kompromistis dari masing-masing musik yang disajikan dan diakomodir dalam repertoar di SKM \#9. Melalui upaya menimbang musik dulu dan kini setidaknya SKM dapat menyuarakan pada generasi muda di Yogyakarta dan sekitarnya bahwa musik keroncong kini dapat dinikmati dan dipelajari oleh anak muda, sekaligus dapat menampik anggapan bahwa musik keroncong hanya dimainkan dan dinikmati oleh generai tua. Dan mari kita tunggu bersama konsep apakah yang akan diusung dalam pergelaran SKM \#10, adakah sesuatu yang baru untuk ditawarkan kepada pendengar ataukah hanya mengulang hal yang sama dari tahun-tahun sebelumnya.

\section{DAFTAR PUSTAKA}

Fiske, John. Memahami Budaya Populer. Yogyakarta: Jalasutra. 2011, pp 28, 30, dan 40.

Ganap, Victor. Krontjong Toegoe. Yogyakarta: Badan Penerbit Institut Seni Indonesia Yogyakarta, 2011, pp 19.

Heryanto, Ariel. terj. Eric Sasono. Identitas dan Kenikmatan: Politik Budaya Layar Indonesia. Jakarta: KPG, 2015, pp 22.

Nehe, Antisipasi Iman. Keberadaan Orkes

Keroncong KKAJ Di Jombang dalam

Virtuoso (Jurnal Pengkajian dan

Penciptaan Musik), Vol. 2, No. 2, November 2019.Program Studi Musik, Fakultas Bahasa dan Seni, Universitas Negeri Surabaya, 2019, pp 71 dan 75.

Novaldi, Dedi, G. R. Lono Lastoro Simatupang, dan Sal Murgiyanto. Pasar Keroncong Kotagede 2017: Sebuah Kajian Event dalam Jurnal Kajian Seni Vol. 5, No. 2 Tahun 2019. Program Studi Pengkajian Seni Pertunjukan dan Seni Rupa, Sekolah 
Pascasarjana, Universitas Gadjah Mada, 2017, pp 197 200, 202, 205 - 206.

Rohidi, Tjetjep Rohendi. Metodologi Penelitian

Seni. Semarang: Penerbit Cipta Prima

Nusantara Semarang, 2011, pp 48.

Soeharto, Achmad Soenardi, dan Samidi Sunurpraptomo. 1996. Serba-Serbi

Keroncong. Jakarta: Penerbit Musika, 1996, pp 44-45.

Sugiyono, Prof. Dr. Metode Penelitian

Pendidikan: Pendekatan Kuantitatif,

Kualitatif, dan $R \& D$. Bandung: Alvabeta.

2015, pp 337 - 345.

Widjajadi, R. Agoes Sri. 2007. Mendayung di Antara Tradisi dan Modernitas: Sebuah Penjelajahan Ekspresi Nudaya Terhadap Musik Keroncong. Yogyakarta: Hanggar Kreator, 2007, pp 3, 4, 23-24, dan 49.

Widyanta, Nugrahanstya Cahya. Efektivitas Keroncong Garapan Orkes Keroncong Tresnawara Terhadap Audiensi Generasi Muda dalam Jurnal Kajian Seni Vol. 3, No.
2 Tahun 2017. Program Studi Pengkajian Seni Pertunjukan dan Seni Rupa, Sekolah Pascasarjana, Universitas Gadjah Mada, 2017, pp 167 - 171.

Widyanta, Nugrahanstya Cahya. Tesis: Gaya Musikal Lagu Keroncong Garapan Orkes Keroncong Tresnawara Yogyakarta. Yogyakarta: Program Studi Pengkajian Seni Pertunjukan dan Seni Rupa, Sekolah Pascasarjana, Universitas Gadjah Mada, 2016, pp 44 dan 57.

Yampolsky, Philip B. Kroncong Revisited: New Evidence from Old Sources, In: Archipel, volume 79. Paris: Musiques d'un Archipel. Sous la direction de Dana Rappoport, 2010, pp 10.

\section{Sumber Elektronik}

http://www.tjroeng.com/?p=373 diunduh 20 Agustus 2019

http://arikantjil.blogspot.co.id/2013/07/keroncong -muda-yk.html diunduh 20 Agustus 2019.

\section{Narasumber}

Andi Prihtyas Toko, wawancara 7 Juni 2018, Yogyakarta. 